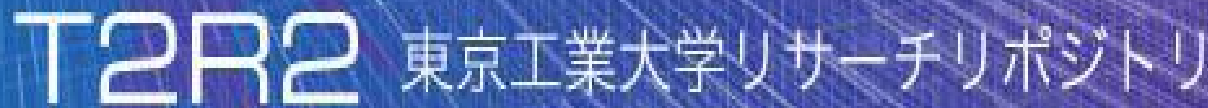

\section{Tokyo Tech Research Repository}

\section{論文 /著書情報 \\ Article /Book Information}

\begin{tabular}{|c|c|}
\hline Title & Fabrication of SIL Array of Glass by Surface-Tension Mold Technique \\
\hline Authors & Tetsuo Kishi, Shuichi Shibata, Tetsuji Yano \\
\hline & 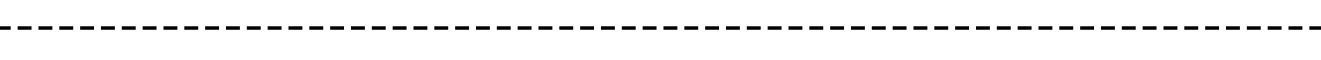 \\
\hline Citation(English) & Proceedings of SPIE, Vol. 6126, No. , pp. 6120P \\
\hline & -ー-ー-ー--- \\
\hline 発行日 /Pub. date & 2006 \\
\hline-------1 & --- \\
\hline DOI & http://dx.doi.org/10.1117/12.647317 \\
\hline & \\
\hline 権利情報 /Copyright & $\begin{array}{l}\text { 本著作物の著作権はSociety of Photo-O ptical Instrumentation } \\
\text { Engineersに帰属します。 } \\
\text { Copyright } 2006 \text { Society of Photo-O ptical Instrumentation Engineers. } \\
\text { One print or electronic copy may be made for personal use only. } \\
\text { Systematic reproduction and distribution, duplication of any material in } \\
\text { this paper for a fee or for commercial purposes, or modification of the } \\
\text { content of the paper are prohibited. }\end{array}$ \\
\hline
\end{tabular}




\title{
Fabrication of SIL array of glass by Surface-tension Mold technique
}

\author{
Tetsuo Kishi*, Shuichi Shibata \& Tetsuji Yano \\ Department of Chemistry and Materials Science, Tokyo Institute of Technology, \\ Ookayama Meguro-ku, Tokyo, 152-8552, Japan
}

\begin{abstract}
A preparation of microlens array of the super-spherical glasses by a combination of the photolithography and the Surface-tension Mold (StM) techniques is shown. A super-spherical lens has been gathering much attention because of its function as a Solid Immersion Lens (SIL) with the super-resolution, which circumvents the optical diffraction limit. StM technique enables the preparation of a micrometer-sized SIL ( $\mu$-SIL) with the desirable shape, and the obtained SILs realize the optical function. In order to develop the optical micro-devices composed of SILs, $\mu$-SIL array module, the micro-fabrication technique of photolithography is combined with StM technique. $\mathrm{Na}_{2} \mathrm{O}-\mathrm{CaO}-\mathrm{SiO}$ glass film is attached to glassy-carbon, and etched into glass tiles after the formation of masks by the photolithography. They are heated up to $800^{\circ} \mathrm{C}$ to self-organize into the super-spherical form of the glass droplets. The obtained lens array is found to be composed of the $\mu$-SILs with the uniform radius and thickness.
\end{abstract}

Keywords: solid immersion lens (SIL), microlens array, super-resolution, surface tension, optical contact, soda-lime glass, wet etching

\section{INTRODUCTION}

Recently, circumventing of the optical diffraction limit is one of the important issues for optical storage, optical microscope and photolithography. Mansfield and Kino ${ }^{1}$ developed the confocal scanning optical microscope with a solid immersion lens (SIL), which is placed close to a sample and form the interaction between the evanescent wave function from a SIL and the surface of the sample. SIL's high spatial resolution and high collection efficiency ${ }^{2,} \quad 3$ are the reasons why they have been gathering much attention in high-density optical storage ${ }^{4-7}$, high-resolution optical microscope ${ }^{2,3,8,9}$ and microscopic spectroscopy ${ }^{10,11}$. The shape of SIL is hemisphere or super-sphere, which is, truncated sphere. The thickness $h$ of the super-spherical SIL is expressed as $h=r(1+1 / n)$, where $r$ and $n$ are radius of curvature and refractive index, respectively, as illustrated in Fig. 1. Extremely high precision of SIL dimension is required to realize high functionals. Yoshita et $a l^{12}$ estimated that the allowance for thickness, and the required processing error of super-spherical SIL are in the order of submicrometer. Nowadays, the glass SILs are made by the conventional preparation technique via a series of the processes; preparation of the spherical glass balls and polishing them to truncate a part of sphere. Very small ranges allowed for SIL dimension have decreased yield of the preparation of the suitable SILs.

Authors' group has developed the novel preparation method of micrometer-sized super-spherical glasses $(\mu-\mathrm{SSG})^{13}$, named Surface-tension Mold (StM) technique. This technique uses the self-organization of glass melts driven by the surface tension of the droplet on the substrate, and $\mu$-SSGs having very smooth spherical surface can be prepared easily. The thickness $h$ depends on the glass materials. When $\mathrm{Na}_{2} \mathrm{O}-\mathrm{CaO}-\mathrm{SiO}_{2}$ glass is used, it has been found that the obtained $\mu$-SSGs satisfy the optical condition of SIL;

$$
n=\frac{r}{h-r}=-\frac{1}{\cos \theta},
$$

where, $\theta$ is a contact angle of $\mu$-SSG in Fig. 1. They also confirmed that the obtained $\mu$-SSG works as the SIL, and was named $\mu$-SIL ${ }^{13}$.

*kis@glass.ceram.titech.ac.jp; phone +81 35734 2523; fax +81 357342845 


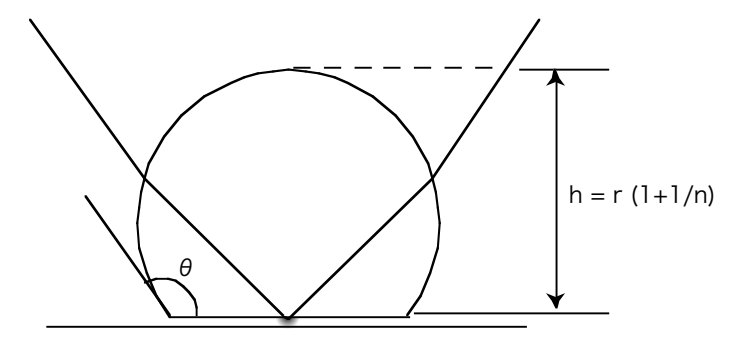

Figure 1. Schematic illustration of super-spherical solid immersion lens, where $h, \mathrm{r}, n$ and $\theta$ are thickness of lens, radius of curvature, refractive index of lens and contact angle, respectively.

On the other hand, when we consider the incorporation of $\mu$-SIL into integrated micro optical system, the arrayed $\mu$ SILs are more suitable than the use as the stand-alone SIL, where the micro-fabrication techniques like photolithography are combined with StM technique. In this work, we report the fabrication process of $\mu$-SIL array. A glass thin film attached on glassy-carbon substrate is etched into the glass tiles by the combination of wet process and dry process. Then they are heated to form $\mu$-SSGs via StM technique. In this process, quite important is that a glass film or tiles must be adhered to the substrate before using the StM technique. We used so-called "optical contact" which realizes an adhesion between optically polished surfaces ${ }^{14}$, a glass film and a glassy carbon substrate. For the etching of glass, a wet chemical etching process was mainly used, which is known as the easy technique for glass micropatterning ${ }^{15-19}$.

\section{EXPERIMENTAL}

\subsection{Materials}

A glass with the composition of $20 \mathrm{Na}_{2} \mathrm{O}-10 \mathrm{CaO}-70 \mathrm{SiO}_{2}$ was prepared by the conventional melting and quenching method. Reagent grade raw materials, $\mathrm{Na}_{2} \mathrm{CO}_{3}, \mathrm{CaCO}_{3}$, and $\mathrm{SiO}_{2}$ were mixed and melted in a platinum crucible at $1550^{\circ} \mathrm{C}$ for 1 hour. In order to ensure the glass homogeneity, the glass was crushed and re-melted for another 3 hour. After second melting, the glass melt was poured onto a wet porous carbon plate heated on a hot plate, then the glass was blown up to a dome shape with about $3 \mathrm{~cm}$ radius and $10 \mu \mathrm{m}$ thickness by the vapor pressure from the carbon plate (Fig.2). The glass dome was cut into about $500 \times 500 \mu \mathrm{m}^{2}$ film, and washed by acetone at $60^{\circ} \mathrm{C}$ and next by distilled water at $100^{\circ} \mathrm{C}$. The dried film was placed between finely polished glassy-carbon substrates with arithmetical average roughness $(\mathrm{Ra})<2 \mathrm{~nm}$, and then the substrates were pressed by the finger. This procedure provides very flat and smooth glass film with $\approx 10 \mu \mathrm{m}$ thickness on the glassy-carbon substrate (Fig.3 (a)).

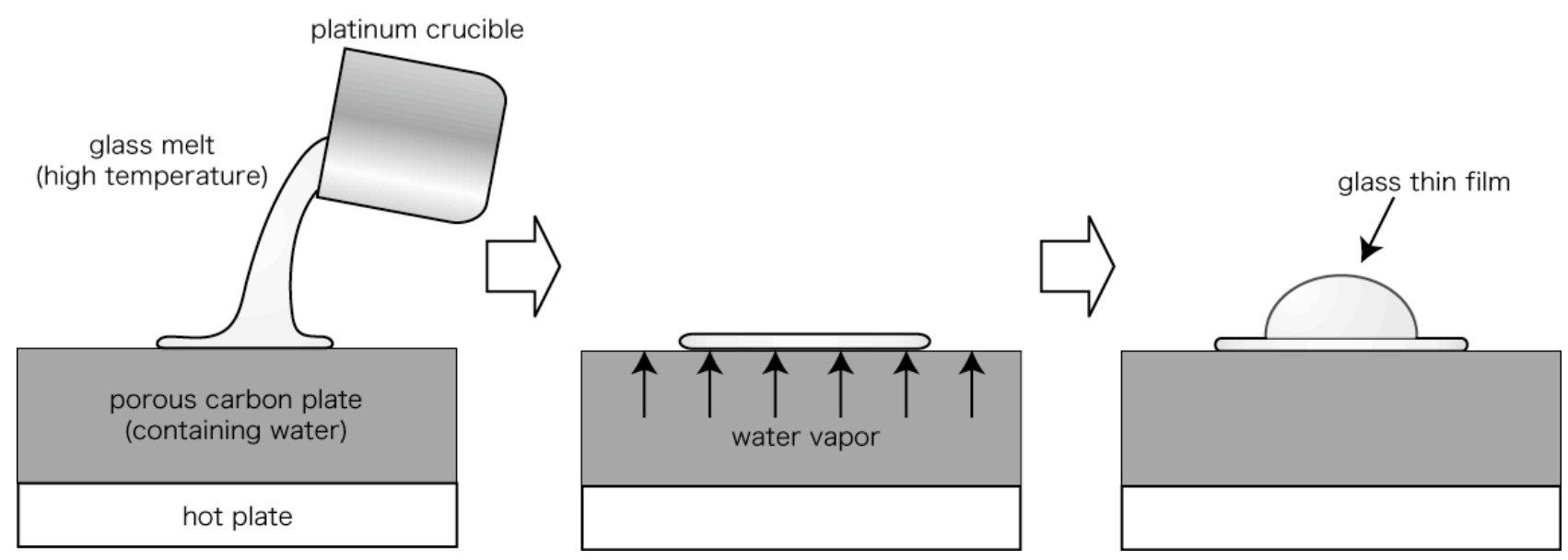

Figure 2. Schematic illustration of the preparation of a glass thin film. 


\subsection{Glass Etching and Surface-tension Mold Technique}

Gold and chromium $(\mathrm{Au} / \mathrm{Cr}$ ) layers were coated successively on the glass film by sputtering in an Ar atmosphere. The thicknesses of $\mathrm{Au}$ and $\mathrm{Cr}$ are $200 \mathrm{~nm}$ and $\sim 40 \mathrm{~nm}$, respectively. The thickness of $\mathrm{Cr}$ layer should be strictly controlled in order to work as the mask protecting the glass under the layer from chemical etching. A negative resist (OMR-85, Tokyo Ohka Kogyo) was spin-coated on the $\mathrm{Au} / \mathrm{Cr}$ layer, and prebaked at $90^{\circ} \mathrm{C}$ for 90 s. Then the substrate was sent to a mask aligner to be exposed at $14 \mathrm{~mW} / \mathrm{cm}^{2}$ for $0.4 \mathrm{~s}$. The pattern of the $10 \times 10$ disk array of $45-\mu \mathrm{m}$ diameter was developed by a $1 \mathrm{~min}$ immersion in a developer solution (OMR DEVELOPER, Tokyo Ohka Kogyo) and rinsed by OMR RINSE (Tokyo Ohka Kogyo) (Fig.3 (b)). After a postbaking at $150^{\circ} \mathrm{C}$ for $40 \mathrm{~min}$, the unmasked Au area was etched by wet etching in solution of $\mathrm{KI}: \mathrm{I}_{2}: \mathrm{H}_{2} \mathrm{O}=2 \mathrm{~g}: 4 \mathrm{~g}: 100 \mathrm{ml}$ at room temperature, and then $\mathrm{Cr}$ was also etched in HICRETCH® (Wako Pure Chemical Industries) (Fig.3(c)).

The glass film was etched in a $5 \%$ buffered hydrogen fluoride (BHF) solution (the mixing ratio of $40 \% \mathrm{NH}_{4} \mathrm{~F}: 48 \% \mathrm{HF}$ is 10:1 in volume) in order to cut into glass tiles (Fig.3 (d)). The etching rate of the glass in the BHF solution is 0.4 $\mu \mathrm{m} / \mathrm{min}$. After the etching, the sample was immersed in $5 \mathrm{M}$ aq. $\mathrm{HCl}$ for $1 \mathrm{~min}$ in order to dissolve away crystallines deposited on the glass surface like calcium fluoride.

Because the bottom of glass film could not be etched completely only by the chemical wet etching, an r.f Ar plasma etching treatment (frequency:13.56MHz)was introduced at the last step of the etching treatment; a last $1 \mu \mathrm{m}$ of the glass film (Fig.3 (e)).

Finally, this tile structure was heated up to $800^{\circ} \mathrm{C}$ and held for $30 \mathrm{~min}$ under the atmosphere of $\mathrm{H}_{2} / \mathrm{N}_{2}=1 / 5$ (StM procedure) in order to change the glass tiles into $\mu$-SILs (Fig.3 (f)), and then cooled to the room temperature. The heating and cooling rates were $10^{\circ} \mathrm{C} / \mathrm{min}$. The obtained sample was observed by the optical microscope and scanning electron microscope (SEM) to know the shape of glass particles (the sphericity and the contact angle of the truncated part) and surface roughness.

(a)

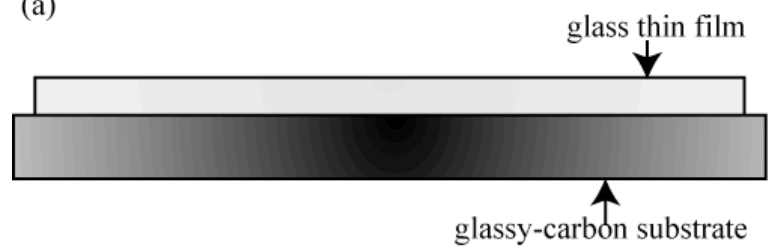

(c)

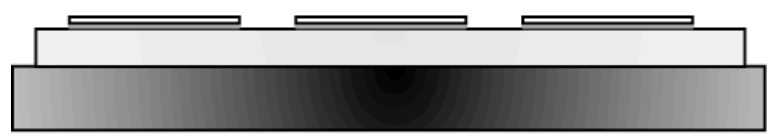

(e)

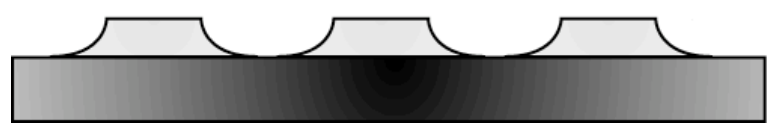

(b)

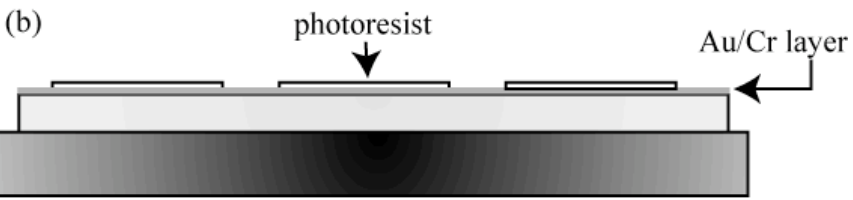

(d)

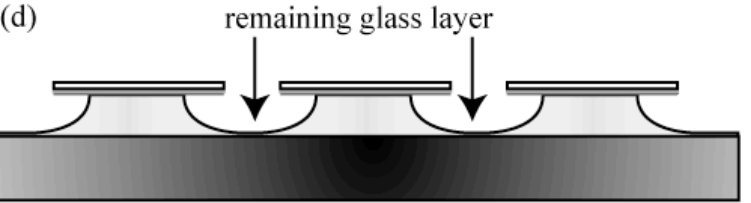

(f)

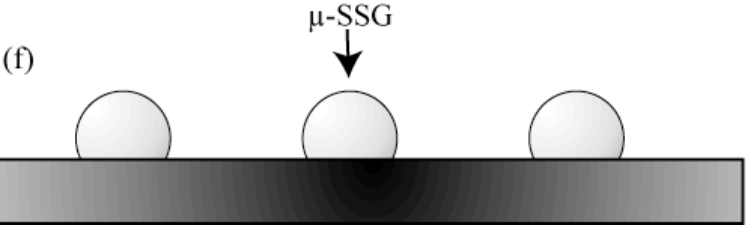

Figure 2. Schematic illustration of the fabrication process of $\mu$-SIL array: (a) a glass film attached on a glassy-carbon substrate; (b) fabrication of $\mathrm{Au} / \mathrm{Cr}$ layer and photoresist pattern on the glass film (c) etching of $\mathrm{Au} / \mathrm{Cr}$ layer to fabricate the etching masks; (d) chamical etching of the glass film by BHF solution; (e) physically etched glass structures; (f) StM treatment of the etched glasses at $800^{\circ} \mathrm{C}$ to form $\mu$-SIL array. 


\section{RESULTS AND DISCUSSION}

For the use of the mask with $10 \times 10$ disk array of $45 \mu \mathrm{m}$ diameter, $\mu$-SSGs with a uniform diameter $27 \pm 2 \mu \mathrm{m}$ could be obtained. However, the yield was as high as $50 \%$. Its reason was due to the elimination of the mask during the wet etching process, or the imperfection of the etching condition. In such a case more than two glass tiles were united into a large $\mu$-SSGs.

Fig. 4 shows the optical images of a $2 \times 2$ array example at the respective step in the fabrication process, sequentially. From Fig. 4 (d), it is confirmed that the aligned transparent $\mu$-SSGs with the diameter ranging from 25 to $29 \mu \mathrm{m}$ are obtained. They are located near the center of the corresponding $\mathrm{Au} / \mathrm{Cr}$ mask. Compared with the etching surface by BHF solution (Fig.4 (a)), Fig. 4(b) has a clean surface by the treatment in aq. HCl; crystallines deposited on the glass surface are dissolved in aq. $\mathrm{HCl}^{18,19}$. If this procedure is omitted, these prevent formation of $\mu$-SSGs with high quality surface. In Fig. 4 (c), the edge of the glass tiles appeared and the tiles are finally isolated each other. However, certain imperfection still remains. This is most likely due to the elimination of the mask, which might be caused by the penetration of the etchant into the interface between the mask and the glass film in the previous wet etching procedure. Diameter deviation of $\mu$-SSGs would decrease further if these imperfect etching errors are reduced.
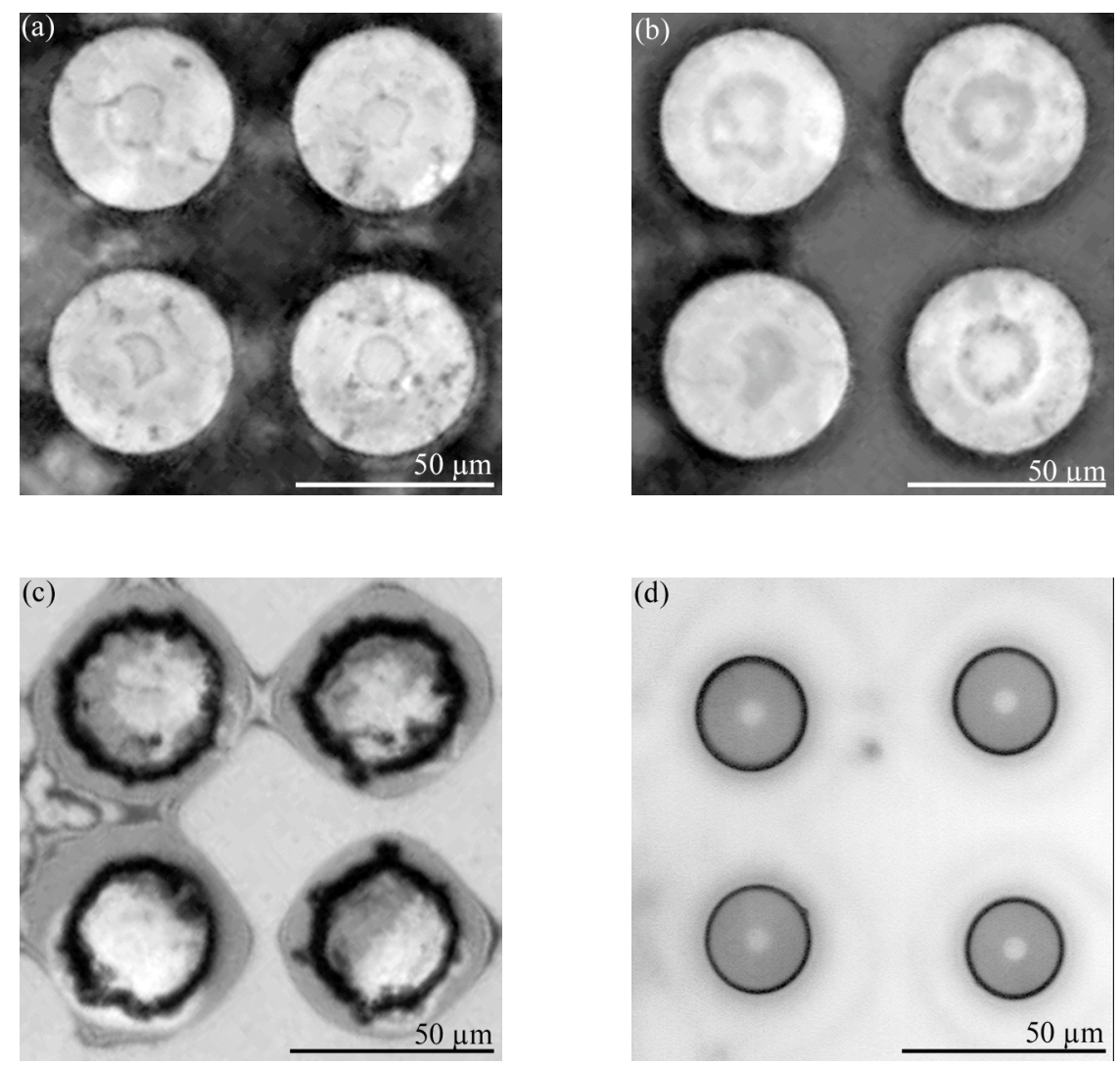

Figure 4. Sequence of the fabrication process to form $\mu$-SSG array. (a) after etching in the BHF solution, (b) after washing with aq. $\mathrm{HCl}$, (c) after etching by Ar plasma and (d) after heat treatment to shape into $\mu$-SSGs.

Fig. 5-1 shows SEM photographs of the prepared 3x3 $\mu$-SSGs. The obtained $\mu$-SSGs are configured as a $\mu$-SIL array. For the comparison, $\mu$-SSGs prepared from soda-lime glass powder with 5-20 $\mu \mathrm{m}$ diameter in our previous work ${ }^{20}$ are shown in Fig. 5-2. The glass powder were placed on a glassy-carbon substrate randomly and heat-treated by StM technique. These photographs show that StM technique enables the formation of $\mu$-SSGs with very smooth surface from the lithographed glass tiles as well as from the glass powders. Compared with Fig.5-2, the obtained $\mu$-SSGs in Fig. 5-1 

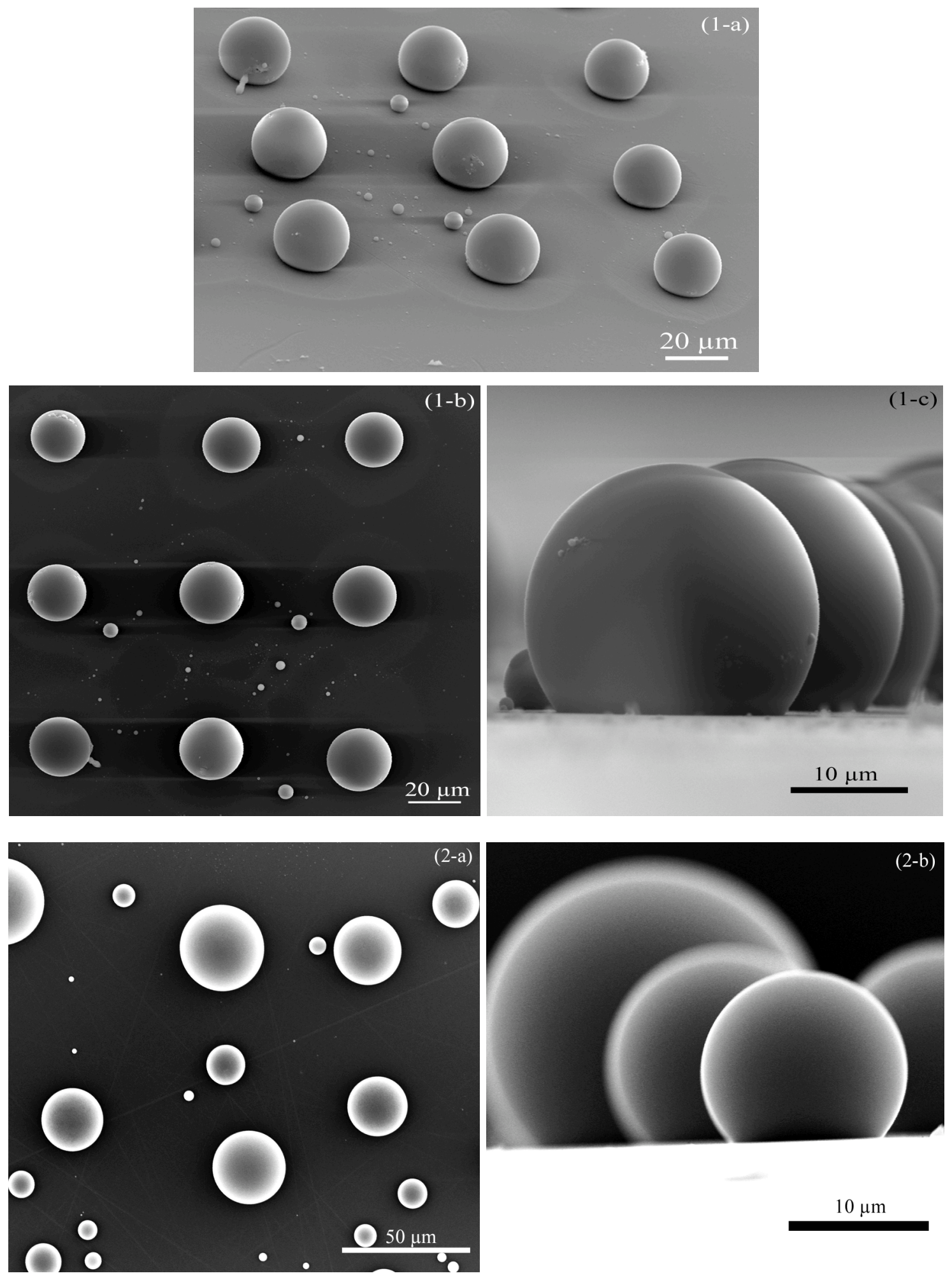

Figure 5. SEM images of the $\mu$-SSGs prepared by the StM technique. (1-a), (1-b) and (1-c) is the overview, top and side view of the obtained $3 \times 3 \mu$-SIL array, respectively. (2-a) and (2-b) is the top and side view of the $\mu$-SSGs prepared from soda-lime glass in a previous work ${ }^{20}$. 
are aligned and the distribution of SIL diameter is reduced well while high sphericity and smooth surface are given. Smaller particles with a few micrometers are found near $\mu$-SILs, which are located around the edge of the glass tiles before StM treatment, and probably due to the imperfect physical etching. On the other hand, the contact angle, which is the most important factor to decide the resolution of lens, was measured from the side view of SEM photographs like Fig. 5-1(c) and was $133 \pm 3^{\circ}$. This satisfies well the optical condition of SIL (eq. (1)), since the refractive index of the glass was 1.52 measured by Abbe's refractometer. In fact, $\mu$-SSGs made from the same glass realized the superresolution of $\mathrm{SIL}^{13}$.

The positions of $\mu$-SSGs were near the center of glass tiles before heat treatment of StM technique, but not coincided with the intended ones; the deviation $7 \mu \mathrm{m}$ was in the maximum. The main reason of this deviation might be the shape of the glass tiles with long tails. Their large contact area with the substrate is to decrease during the StM procedure (Fig. 6 (a)). Irregular shapes of the edge line of the contact face might induce the irregular move of the droplets ${ }^{21}$. Therefore, it is desired that the contact area does not change largely during the heat treatment of StM technique. Fig. 6 (b) illustrates one of the ideal processes to form a $\mu$-SIL array precisely. When the glass tiles have cylindrical rod shape with aspect ratio of 1.6, the contact area doesn't change before and after StM technique. Such micrometer-sized cylindrical glasses with high aspect ratio would be realized by chemical dry etching like reactive ion etching ${ }^{22}$.

In order to integrate the $\mu$-SIL array into optical systems, $\mu$-SILs should be fixed with a certain rigid media like resin to obtain $\mu$-SIL array module. In case of $\mu$-SIL of $\mathrm{Na}_{2} \mathrm{O}-\mathrm{CaO}-\mathrm{SiO}_{2}$ glass in this study, a top half of $\mu$-SIL has to be uncovered for large NA (numerical aperture) in Fig. 1. Needless to say, the anti-reflection coating on the top half surface provides the higher collection efficiency. Modulation of a $\mu$-SIL array is under investigation to demonstrate its functionality of high optical resolution.

(a)
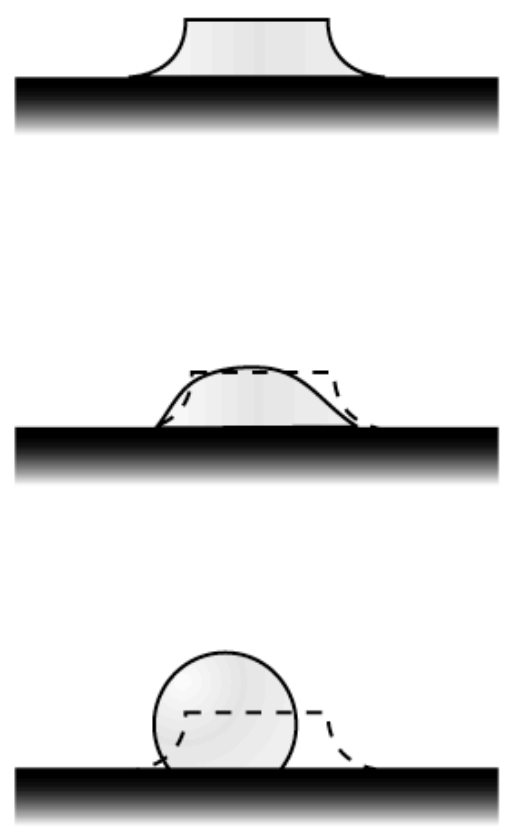

(b)
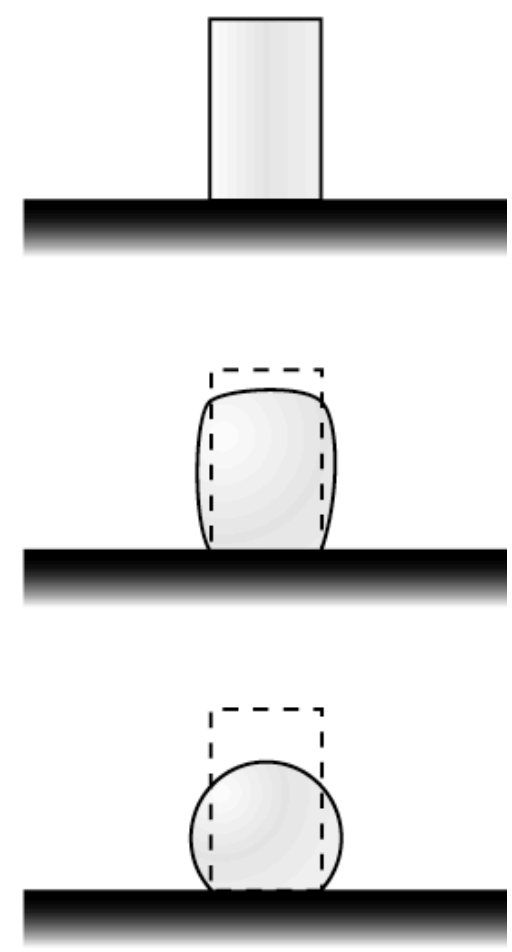

Figure 6. Schematic images of transformation of glass tiles. (a) A 10- $\mu \mathrm{m}$ thick wide-based tile whose diameter of the top is $25 \mu \mathrm{m}$, (b) a cylindrical shape of glass with aspect ratio of 1.6. 


\section{CONCLUSION}

In this paper, we presented the novel fabrication process for $\mu$-SIL array of glass using a combination of the photolithography and StM technique. We confirmed that the obtained sample had the functionality of SIL array from the shape and refractive index of the composing $\mu$-SILs. The average diameter of fabricated $\mu$-SILs was $27 \pm 2 \mu \mathrm{m}$, and the maximum deviation of the position of lens was $7 \mu \mathrm{m}$. These results indicate that the StM technique can realize fabrication of arrayed $\mu$-SILs combined with micropatterning technology.

\section{ACKNOWLEDGEMENTS}

This research was supported by Japan Society for the Promotion of Science (JSPS).

\section{REFERENCES}

1. S.M. Mansfield and G.S. Kino, "Solid immersion microscope," Appl. Phys. Lett. 57 2615-2616 (1990).

2. T. Sasaki, M. Baba, M. Yoshita and H. Akiyama, "Application of Solid Immersion Lens to High-Resolution Photoluminescence Imaging of Patterned GaAs Quantum Wells," Jpn. J. Appl. Phys. Lett. 36 L962-L964 (1997).

3. K. Koyama, M. Yoshita, M. Baba, T. Suemoto and H. Akiyama, "High collection efficiency in fluorescence microscopy with a solid immersion lens," Appl. Phys. Lett. 75 1667-1669 (1999).

4. S.M. Mansfield, W.R. Studenmund, G.S. Kino and K. Osato, "High-numerical-aperture lens system for optical storage," Opt. Lett. 18 305-307 (1993).

5. B.D. Terris, H.J. Mamin, D. Rugar, W.R. Studenmund and G.S. Kino, "Near-field optical data storage using a solid immersion lens," Appl. Phys. Lett. 65 388-390 (1994).

6. I. Ichimura, K. Kishima, K. Osato, K. Yamamoto, Y. Kuroda, K. Saito, "Near-Field Phase-Change Optical Recording of 1.36 Numerical Aperture," Jpn. J. Appl. Phys. 39 962-967 (2000).

7. S. Imanishi, M. Takeda, M. Yamamoto, N. Mukai, K. Takagi, T. Kono, "Near-Field Recording with a $266 \mathrm{~nm}$ Laser for Disc Mastering Process," Jpn. J. Appl. Phys. 42 1105-1109 (2003).

8. D.A. Fletcher, K.B. Crozier, C.F. Quate, G.S. Kino, K.E. Goodson, D. Simanovskii, D.V. Palanker, "Near-field Infrared Imaging with a microfabricated solid immersion lens," Appl. Phys. Lett. 77 2109-2111 (2000).

9. D.A. Fletcher, K.B. Crozier, K.W. Guarini, S.C. Minne, G.S. Kino, C.F. Quate, K.E. Gooson, "Microfabricated silicon solid iimmersioon lens," J. Micro. Sys. 10 No.3 450-459 (2001).

10. M. Yoshita, N. Kondo, H. Sasaki, M. Baba and H. Akiyama, "Large terrace formation and modulated electronic states in (110) GaAs quantum wells," Phy. Rev. B 6375305 (2001).

11. Q. Wu, R.D. Grober, D. Gammon and D.S. Katzer, "Imaging Spectroscopy of Two-Dimensional Excitons in a Narrow GaAs/AlGaAs Quantum Well," Phys. Rev. Lett. 83 2652-2655 (1999).

12. M. Yoshita, K. Koyama, Y. Hayamizu, M. Baba and H. Akiyama, "Improved High Collection Efficiency in Fluorescence Microscopy with a Weirstrass-Sphere Solid Immersion Lens," Jpn. J. Appl. Phys. 41 L858-860 (2002).

13. T. Yano, T. Kishi and S. Shibata, submitted.

14. H. Vaart, H.I. Smith and C.H. Mass, "High Efficiency Polarization Reversal of Magnetoelastic Waves in YIG by Optical-contact Bonding of YAG Disks," Appl. Phys. Lett. 9 439-441 (1966).

15. P.C. Simpson, A.T. Woolley, R.A. Mathies, "Microfabrication Technology for the Produtcion of Capillary Array Electrophoresis Chips," Biomed Microdevices 1 7-25 (1998).

16. C. Iliescu, J. Miao, F.E.H. Tay, "Stress control in masking layers for deep wet micromachining of Pyrex glass," Sens. Actuator A 117 286-292 (2005).

17. Z. Xue and H. Qiu, "Integrating micromahined fast response temperature sensor array in a glass microchannel," Sens. Actuator A 122 189-195 (2005).

18. C. Iliescu, J, Jing, F.E.H. Tay, J. Miao and T. Sun, "Characterization of masking layers for deep wet etching of glass in a improved HF/HCl solution," Surf. Coat. Technol. 198 314-318 (2005). 
19. M. Stjernstöm, and J. Roeraade, "Method for fabrication of microfluidic systems in glass," J. Micromech. Microeng. 8 33-38 (1998).

20. T. Kishi, S. Shibata and T. Yano, "Preparation of micrometer-sized super-spherical glasses for optical resonator," Proc. XX International Congress on Glass, o-14-022, (2004).

21. J.F. Joanny and P.G. De Gennes, “A model for contact angle hysterisis,” J. Chem. Phys. 81 552-562 (1984).

22. X. Li, T. Abe and M. Esaki, "Deep reactive ion etching of Pyrex glass using SF 6 plasma," Sens. Actuators A 87 139-145 (2001). 